\title{
Correction to: Convergent and discriminative validity of the Frail-VIG index with the EQ-5D-3L in people cared for in primary health care
}

\author{
Juan-José Zamora-Sánchez ${ }^{1,2}$, Edurne Zabaleta-del-Olmo ${ }^{1,3,4,5^{*}}$, Vicente Gea-Caballero ${ }^{6,7}$, Iván Julián-Rochina ${ }^{8,9}$, \\ Gemma Pérez-Tortajada ${ }^{10}$ and Jordi Amblàs-Novellas ${ }^{11}$
}

\section{Correction to: BMC Geriatr 21, 243 (2021) \\ https://doi.org/10.1186/s12877-021-02186-x}

In the original publication [1] there was an incorrect funding acknowledgement. In this correction article the correct and incorrect funding acknowledgement are published. The updated information is shown in bold. The original article has been updated.

\section{Incorrect funding}

- This research was supported by the Health Department grant number (SLT008/18/00011) from the Generalitat of Catalunya (Spain) and by a grant from the Territorial Management of Barcelona of the Institut Català de la Salut (Catalan Institute of Health) to the first author (JJZS) in the 2018 edition. The funders had no role in review design, decision to publish, or preparation of this manuscript.

\section{Correct funding}

- This research was supported by, the Health Department grant number (SLT008/18/00011) from the Generalitat of Catalunya (Spain), by a grant from the Territorial Management of Barcelona of the Institut Català de la Salut (Catalan Institute of

The original article can be found online at https://doi.org/10.1186/s12877021-02186- $x$

* Correspondence: ezabaleta@idiapjgol.org

'Gerència Territorial de Barcelona, Institut Català de la Salut, Gran Via Corts Catalanes 587 àtic, 08007 Barcelona, Spain

${ }^{3}$ Fundació Institut Universitari per a la recerca a l'Atenció Primària de Salut Jordi Gol i Gurina (IDIAPJGol), Barcelona, Spain

Full list of author information is available at the end of the article
Health) to the first author (JZZS) in the 2018 edition, and by the MUTUAMCONVIURE Foundation's Research Award in Social and Health Care (18th Edition). The funders had no role in review design, decision to publish, or preparation of this manuscript.

\begin{abstract}
Author details
${ }^{1}$ Gerència Territorial de Barcelona, Institut Català de la Salut, Gran Via Corts Catalanes 587 àtic, 08007 Barcelona, Spain. ${ }^{2}$ School of Nursing, Universitat de Barcelona, Barcelona, Spain. ${ }^{3}$ Fundació Institut Universitari per a la recerca a I'Atenció Primària de Salut Jordi Gol i Gurina (IDIAPJGol), Barcelona, Spain. ${ }^{4}$ Universitat Autònoma de Barcelona, Bellaterra, Cerdanyola del Vallès, Spain. ${ }^{5}$ Nursing Department, Faculty of Nursing, Universitat de Girona, Girona, Spain. ${ }^{6}$ Nursing school "La Fe", Valencia, Spain. ${ }^{7}$ GREIACC Research Group, Instituto de Investigación Sanitaria La Fe, Valencia, Spain. ${ }^{8}$ Nursing Department, Universitat de Valencia, Valencia, Spain. ${ }^{9}$ Fragilidad y Deterioro Cognitivo (FROG) Research Group, Universitat de Valencia, Valencia, Spain. ${ }^{10}$ Primary care centre "Fondo", Gerència Territorial Metropolitana Nord, Institut Català de la Salut, Santa Coloma de Gramenet, Spain. ${ }^{11}$ Central Catalonia Chronicity Research Group (C3RG), Centre for Health and Social Care Research (CESS), Universitat de Vic - University of Vic-Central University of Catalonia (UVIC-UCC), 08500 Vic, Spain.
\end{abstract}

Published online: 12 July 2021

\section{Reference}

1. Zamora-Sánchez JJ, Zabaleta-del-Olmo E, Gea-Caballero V, et al. Convergent and discriminative validity of the Frail-VIG index with the EQ-5D-3L in people cared for in primary health care. BMC Geriatr. 2021;21:243. https:// doi.org/10.1186/s12877-021-02186-x.

C C The Author(s). 2021 Open Access This article is licensed under a Creative Commons Attribution 4.0 International License, which permits use, sharing, adaptation, distribution and reproduction in any medium or format, as long as you give appropriate credit to the original author(s) and the source, provide a link to the Creative Commons licence, and indicate if changes were made. The images or other third party material in this article are included in the article's Creative Commons licence, unless indicated otherwise in a credit line to the material. If material is not included in the article's Creative Commons licence and your intended use is not permitted by statutory regulation or exceeds the permitted use, you will need to obtain permission directly from the copyright holder. To view a copy of this licence, visit http://creativecommons.org/licenses/by/4.0/ The Creative Commons Public Domain Dedication waiver (http://creativecommons.org/publicdomain/zero/1.0/) applies to the data made available in this article, unless otherwise stated in a credit line to the data. 